\title{
Chemotactic and Leukocytosis-inducing Activities of Eel Complement
}

\author{
Takaji IIDA and Hisatsugu WAKABAYASHI \\ Dept. of Fish., Fac. of Agr., Univ. of Tokyo, 1-1-1, Yayoi, \\ Bunkyo-ku, Tokyo 113, Japan
}

(Received November 20, 1987)

\begin{abstract}
Biological activities of eel complement activated through the alternative pathway, namely, chemotactic activity and leukocytosis-inducing activity, were investigated.

The normal eel sera were mixed with zymosan or formalin-killed cells of selected bacteria (Escherichia coli, Edwardsiella tarda or Vibrio anguillarum) and incubated at $25^{\circ} \mathrm{C}$ for $60 \mathrm{~min}$. The sera were separated from zymosan or bacterial cells by centrifugation. And then, this treated sera were heated at $50^{\circ} \mathrm{C}$ for $30 \mathrm{~min}$.

Chemotactic activity of the treated sera were determined by the modified Boyden chamber method. The distance of eel neutrophil migration toward the treated sera were significantly different from that toward the inactivated sera.

The peripheral neutrophils increased in number rapidly 6-9 $\mathrm{hr}$ after the intraperitoneal injection with the treated sera. There appeared to be the leukocytosis-inducing activity in the treated sera.

These biological activites of eel complement indicated in this study may play an important role in the non-specific defence mechanism of eel.
\end{abstract}

For the non-specific defence mechanism of mammals in the early stage of infection, it is thought that the serum components, for example, C-reactive protein, transferrin, interferon, lysozyme and complement, are very important. Complement is especially critical, because it possesses various biological activities by the activation through the alternative pathway (JoHNSTON, 1977). These activities include opsonization, bactericidal activity, chemotactic activity and leukocytosisinducing activity. The non-specific defence mechanism of fish is thought to be similar to that of mammals (INGRAM, 1980).

In earlier papers, we reported that eel complement exhibited the bactericidal activity and opsonization through the alternative pathway (IIDA and WaKaBAYASHI, 1983; MoRitomo et al., 1988). The purpose of this study was to demonstrate the biological activites of eel complement, namely, chemotactic and leukocytosis-inducting activities, through the alternative pathway.

\section{Materials and Methods}

\section{Sera and neutrophils}

Eels, Anguilla japonica, weighing approximately $200 \mathrm{~g}$ were maintained in $100 \mathrm{l}$ aquarium at $25^{\circ} \mathrm{C}$. After acclimation for 5-7 days, the fish were bled from bulbus arteriosus. Sera were separated by centrifugation and pooled from three fish. A half of the sera was stored at $-80^{\circ} \mathrm{C}$ until used, while the rest was inactivated by heating at $50^{\circ} \mathrm{C}$ for $30 \mathrm{~min}$.

In order to isolate neutrophils for chemotactic activity test, blood was taken from bulbus arteriosus by means of heparinized syringe. The fish had been intraperitoneally injected with $2 \%$ soultion of casein $12 \mathrm{hr}$ before being bled, because NAGAMURA and WAKABAYASHI (1985b) reported that neutrophils of the fish intraperitoneally injected with the casein soultion were activated in migration. The procedure for isolation of neutrophils from peripheral blood was folowed that used by NAGAMURA and WAKABAYSHI (1985a). The isolated neutrophils were washed three times with Hanks' balanced salt solution and resuspend- 
ed at a density of $10^{5}-10^{6}$ cells $/ \mathrm{m} l$ in Engle's MEM with the inactivated eel sera (final concentration $1 \%$ ). The rate of neutrophils in the suspended cells was more than $60 \%$.

\section{Preparation of treated sera}

A mixture of $1 \mathrm{~m} l$ of the normal sera and $25 \mathrm{mg}$ of zymosan, which is known as an activator for the alternative complement pathway, or $10 \mathrm{mg}$ of formalin-killed bacteria (Escherichia coli IAM 1239, Edwardsiella tarda FPC 381 or Vibrio anguillarum SG 7701) were incubated at $25^{\circ} \mathrm{C}$ for $60 \mathrm{~min}$ with occasionally shaking. The sera was separated from zymosan or bacterial cells by centrifugation. This treated sera was heated at $50^{\circ} \mathrm{C}$ for $30 \mathrm{~min}$ and stored in refrigerator.

\section{In vitro chemotactic activity}

In vitro migration of neutrophils toward the treated sera was measured by using a modified Boyden chamber as described by NAGAMURA and WAKABAYASHI (1985b). This consisted of two unattached chamber separated by a filter $(3 \mu \mathrm{m}$ pore size, Millipore Fillter Corporation, USA), with neutrophil suspension in the upper chamber and with the treated sera (final concentration $1 \%$ in Eagle's MEM) in the lower chamber. The migration distances of 10 cells of the farthest neutrophils in the filter were measured under a microscope.

The in vitro chemotactic activity test was done at 2 different bacterial densities. In the first experiment, the bacterial density in the normal sera was $10 \mathrm{mg} / \mathrm{ml}$, while in the escond experiment: $100 \mathrm{mg} / \mathrm{m} l$.

\section{Leukocytosis-inducing activity}

A small amount of blood was sampled from caudal vessel every $3 \mathrm{hr}$ for $24 \mathrm{hr}$ after the intraperitoneal injection with the treated sera $(0.2$ $\mathrm{m} l /$ fish). The blood smears were air-dried and stained with May-Grünwald Giemsa and Periodic acid Shiff reagent. The number of neutrophils relative to 5000 erythrocytes was counted under a microscope.

\section{Results}

In vitro chemotactic activity

In the first experiment, the migration distance
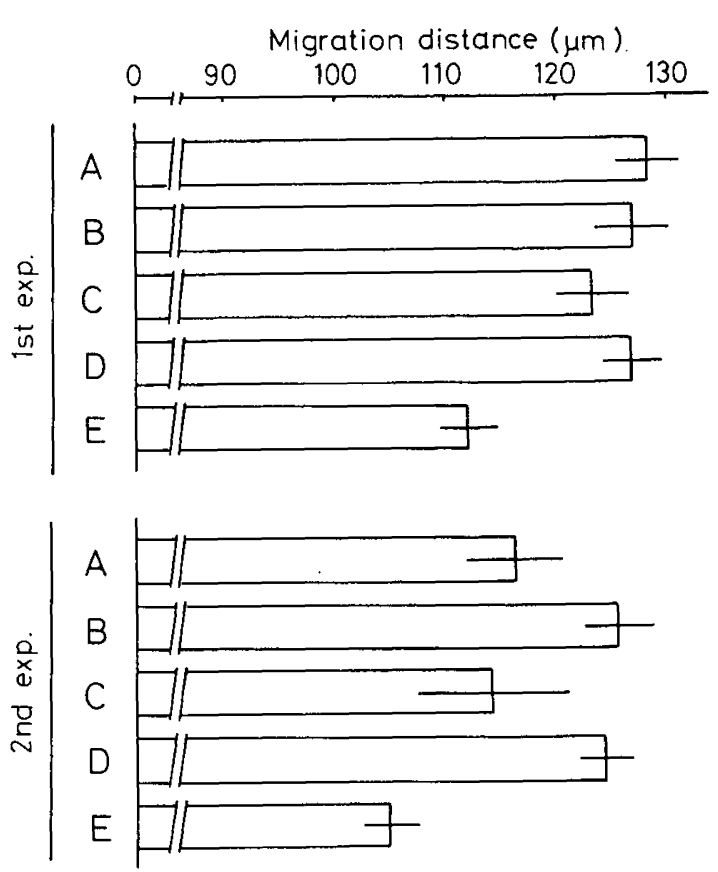

Fig. 1. Migration distance of isolated eel neutrophils toward the following sera: A, incubated with zymosan; B, incubated with Escherichia coli; C, incubated with Edwardsiella tarda; D, incubated with Vibrio anguillarum; E, inactivated. Neutrophils used at each experiment were isolated from one fish.

of neutrophils toward the sera incubated with zymosan was $128 \mu \mathrm{m}$, and those toward the sera incubated with $E$. coli, E. trada or $V$. anguillarum were 127,123 and $127 \mu \mathrm{m}$, respectively. On the other hand, the migration distance of neutrophils toward the incativated sera was $113 \mu \mathrm{m}$. In the second experiment, the migration distance of neutrophils toward the sera incubated with zymosan, E. coli, E. tarda or V. anguillarum were $116,125,114$ and $124 \mu \mathrm{m}$, respectively, and that toward the inactivated sera was $105 \mu \mathrm{m}$ (Fig. 1). In the first and second experiments, the distance of neutrophil migration toward the sera incubated with zymosan or the bacterial cells were significantly different from that toward the inactivated sera by Mann-Whittney $U$ test $(P<0.01)$. The treated sera had the chemotactic acivity.

\section{Leukocytosis-inducing activity}

Peripheral neutrophils increased in number 


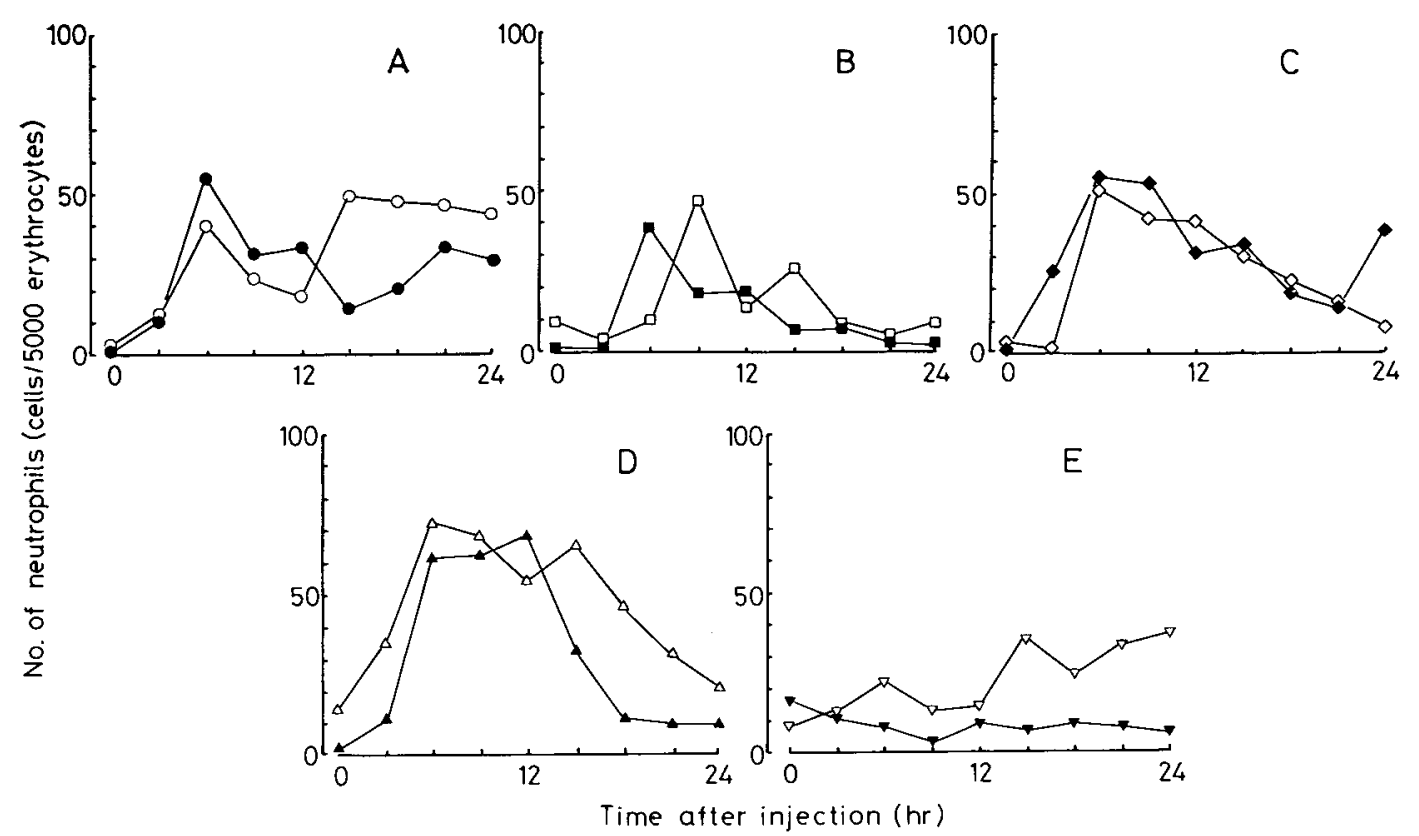

Fig. 2. Changes with time in the number of peripheral neutrophils after the intraperitoneal injection with following sera: A, incubated with zymosan; B, incubated with Escherichia coli; C, incubated with Edwardsiella tarda; D, incubated with vibrio anguillarum; E, inactivated. Each symbol indicates the result from a fish.

rapidly $6 \mathrm{hr}$ after the intraperitoneal injection with the sera incubated with zymosan. When the eel was interaperitoneally injected with the sera incubated with the bacterial cells, peripheral neutrophils also increased in number rapidly 6 or $9 \mathrm{hr}$ after the injection. But the rapid increase in the number of peripheral neutophils was not observed after the intraperitoneal injection with the inactivated sera (Fig. 2). The treated sera exhibited leukocytosis-inducing activity.

\section{Discussion}

Many biological activities of complement are produced by the activation through the classical or alternative pathway, and the activities are exhibited by the fragments of complement components. Chemotactic activity and leukocytosis-inducing activity are induced by $\mathrm{C} 5 \mathrm{a}$ and C3e, respectively (FEARON and WONG, 1983).

NAKANO et al. (1981) purified C5 fragment from fish complement. Their report supports that fish complement might possess chemotactic ability similar to mammalian C5a. In fact, chemotaxis generated by activating fish complement has been demonstrated (GRIFFIN, 1984). SUZUKI (1986) indicated that chemotactic response of eel neutrophils was induced by the reaction of the blood plasma with zymosan, Sephadex and inulin, which are activators for the alternative complement pathway. In the present study, we also showed that eel neutrophils migrated directionally toward the sera incubated with zymosan or bacterial cells. This result suggested that eel complement has C5a-like substance.

In mammals, $\mathrm{C} 3 \mathrm{e}$ derived from $\mathrm{C} 3 \mathrm{c}$ fragment of $\mathrm{C} 3$ has the ability to evoke leukocytosis, and $\mathrm{C} 3 \mathrm{e}$ differs from $\mathrm{C} 3 \mathrm{a}$ and $\mathrm{C} 5 \mathrm{a}$ in several respects (Ghebrehiwet and Müller-Eberhard, 1979). Moreover, FEARON and WONG (1983) indicated that the leukocyte which had a receptor against C3e was neutrophil. Most of Japanese eel granulocytes seemed to be neutrophil (HosHinA, 1962), and the tendency of change with time in the number of peripheral neutrophils in the present study was similar to that in mammals reported by GHEBREHIWET and MülLER-EBERHARD (1979). This facts implied that there was C3e-like activity 
in the activated eel sera. After bacteria infect eel organ, peripheral neutrophils increases in number (NAGAMURA and WAKABAYASHI, 1983). The C3e-like substance is thought to be partly related to this phenomenon.

As mentioned above, when eel complement is activated through the alternative pathway, the biological activities, that is, chemotactic activity and leukocytosis-inducting activity, are generated. These activities may play an important role in the non-specific defence mechanism of eel against bacterial infections.

MoRitomo et al. (1988) reported that opsonization of $E$. tarda with normal eel sera was not observed. But in this study, the sera incubated with $E$. tarda cells possessed the biological activities. From these results, it is suggested that although eel complement is activated by $E$. tarda cells, opsonin of eel complement can not adhere to $E$. tarda cell surface.

\section{Acknowledgements}

We express our sincere thanks to Dr Douglas P. Anderson, United States Fish and Wildlife Service, for reviewing the manuscript. This work was partly supported by a grant from the Ministry of Education, Science and Culture, grant No. 61480067.

\section{References}

Fearon, D. T. and W. W. Wong (1983): Complement ligand-receptor interactions that mediate biological responses. Ann. Rev. Immunol., 1, 243 271.

GHebrehiwet, B. and H. J. Müller-Eberhard (1979): C3e: An acidic fragment of human C3 with leukocytosis-inducing activity. J. Immunol., 123, 616-
621.

Griffin, B. R. (1984): Random and directed migration of trout (Salmo gairdneri) leukocytes: Activation by antibody, complement, and normal serum components. Dev. Comp. Immunol., 8, 589-597.

Hoshina, T. (1962): Study on red fin disease of eel. J. Tokyo Univ. Fish. Spe. Ed., 6, 1-104. (In Japanese)

IIDA, T. and H. WAKABAYASHI (1983): Bactericidal reaction by the alternative pathway of fish complement. Fish Pathology, 18, 77-83. (In Japanese)

InGRAM, G. A. (1980): Substances involved in the natural resistance of fish to infection-A review. $J$. Fish Biol., 16, 23-60.

JoHnston, R. B. (1977): Biology of the complement system with particular reference to host defence against infection-A review. In: Malnutrition and the immune response (R. M. Suskind, ed.), pp. 295-307, New York, Raven Press.

Moritomo, T., T. IIdA and H. Wakabayashi (1988): Chemiluminescense of neutrophils isolated from peripheral blood of eel. Fish Pathology, 23, 49-53.

Nagamura, Y. and H. WaKabayashi (1983): Periodic acid-shiff reaction of neutrophils of the eel, Anguilla japonica. Fish Pathology, 17, 269-280. (In Japanese)

Nagamura, Y. and H. Wakabayashi (1985a): A method for separating neutrophils from eel blood. Fish Pathology, 20, 65-66. (In Japanese)

Nagamura, Y. and H. WaKabayashi (1985b): Changes in glycogen content of neutrophils in eel, Anguilla japonica, by bacterial infection. Fish Pathology, 20, 389-394.

Nakano, M., S. Natsuume-Sakai and M. Takahashi (1981): The complement system in rainbow trout (Salmo gairdneri) II. Purification and characterization of the fifth component (C5). J. Immunol., 126, 1495-1498.

SuzuKI, Y. (1986): Neutrophil chemotactic factor in eel blood plasma. Nippon Suisan Gakkaishi, 52, 811-816. 